\title{
Influence of the Number of Coil on the Accelerated-Type Wave Energy Generation System
}

\author{
Hu Chen ${ }^{1,2,3}$, Zhifei Ji ${ }^{1,2,3, *}$, Yusheng ${ }^{1,2,3} \mathrm{Hu}$ and Min Lin $^{1}$ \\ ${ }^{1}$ College of Mechanical and Energy Engineering, Jimei University, Xiamen, Fujian, 361021, France \\ ${ }^{2}$ Fujian Province Key Laboratory of Ocean Renewable Energy Equipment, Xiamen, Fujian, 361021, China \\ ${ }^{3}$ Fujian Province Key Laboratory of Energy Cleaning Utilization and Development, Xiamen, Fujian, 361021, China
}

\begin{abstract}
This paper proposed a pulley-buoy accelerated type linear wave power generation system, and verifies its feasibility and effectiveness through experiments. Compared with traditional three-phase wave energy converter, the process of energy transfer was cancelled in the pulley-buoy accelerated type linear wave power generation system, wave energy was converted into electrical energy through the movement of float directly. In the system, the pulley assembly increased the velocity of the float and the generating capacity of the linear generation system, thereby increasing its conversion efficiency. In the experiment, an undersized pulley-buoy accelerated type linear wave power generation system and a swing wave-making system were built in the laboratory. The experiment explored the influence of the number of the stator coil on the power generation performance of the system, and results showed that within the scope of this research, increasing the stator coils to a certain extent could effectively raise the efficiency of wave energy conversion and improve the generation performance of the pulley-buoy accelerated type linear wave power generation system. This research provides valuable experience for the actual application and effective operation of wave energy conversion system.
\end{abstract}

\section{Introduction}

As a sustainable energy source, wave energy has received widespread attention worldwide for its high energy density, large reserves and wide distribution range $[1,2]$. In recent years, there have been many successful cases of wave energy technology in many countries abroad, such as the "PowerBuoy" in the United States, the "OE buoy" and the "Wavebob" oscillating buoy-type wave energy converter in Ireland, the "Oceanlinx" Oscillating Water Column wave energy converter in Australia, the "Oyster" wave surge converter and the "Pelamis" raft-type wave energy converter in the UK, the "Penguin" boat-type buoy wave energy converter and the "WaveRoller" wave surge converter in Finland, and the "Wave Star" multi-float buoy wave energy converter and the "Wave Dragon" doubly-curved ramp wave energy converter in the Denmark [3-5]. With the support of national plans and special funds, China's wave energy technology has developed rapidly, and some wave energy converters have been in actual test or put into operation, mainly including the duck wave energy converter and the sharp eagle wave energy converted developed by the Guangzhou Energy Research Institute, the swing-buoy wave energy converter developed by the National Ocean Technology Center, the combined oscillating float wave energy converter developed by the Ocean University of China, as well as the raft-type, flap-type, hydraulic and pneumatic wave energy power generation devices developed by other colleges and universities [6-11]. However, most wave energy generation devices home and abroad have the problems of low power generation efficiency, poor structural reliability, and unstable system operation, and these problems are still not well resolved, which hinders the commercial operation wave power technology to a certain extent.

To better improve the efficiency of the wave energy generation device, a two-phase pulley-buoy-accelerated linear wave energy generation with only two-phase energy conversion is designed in this paper. In the system, an oscillating float is directly connected with a mover of a linear power generator, wave energy is converted into electricity directly as the float moves, and no intermediate energy transfer or conversion process is needed. The introduction of the pulley assembly can increase the mover's velocity of cutting the magnetic induction line in the leaner power generation system by several times. According to the principle of electromagnetic induction, the power generation of the linear power generation system is increased, so as to finally achieve the goal of improving the wave energy conversion efficiency of the system. In order to verify the feasibility and effectiveness of the pulley-buoyaccelerated wave energy generation system, an undersized pulley-buoy-accelerated wave energy generation system prototype and a swing wave-making system are built under laboratory conditions. By

\footnotetext{
Corresponding author: jizhifei@jmu.edu.cn
} 
simulating different wave conditions, the experiment studies the influence of the number of stator coils on the power generation performance of the system.

\section{Systematic introduction}

\subsection{Pulley-buoy-accelerated linear wave energy generation system}

The two-phase pulley-buoy-accelerated linear wave energy generation system designed in this paper is shown in Figure 1. The system consists of a linear generation system, a pulley assembly and a door frame. In the pulley-buoy-accelerated linear wave energy generation system, wave energy is firstly converted into mechanical energy of the float, then the float drives the mover of the linear power generation system to move, and the mechanical energy of the float is converted into electrical energy as the mover cuts the magnetic induction lines. In the system, the wave drives the float to move, and electricity is generated directly from the movement of the float without energy transfer or conversion. What's more, the pulley assembly increases the velocity of the float and amplifies the velocity of the mover in the linear power generation system by several times. According to the principle of electromagnetic induction $(\mathrm{E}=\mathrm{BLV}, \mathrm{E}$ represents the induced electromotive force; $\mathrm{B}$ represents the magnetic induction intensity; L represents the effective length; V represents the cutting magnetic induction linear velocity), when other conditions remain unchanged, the increase of the velocity of cutting the magnetic induction lines leads to an increase in the power generation of the linear power generation system, which ultimately improves the wave energy conversion efficiency of the system.



Figure 1 Pulley-buoy-accelerated linear wave energy generation system

By using the linear generation system, the movement of the float is converted into electricity directly. The selfmade linear generation system is composed of a mover and a stator, wherein the mover consists of a ring magnet, a ring partition block and an aluminum spindle, and the stator is a coil. When the float moves under the action of waves, the pulley assembly directly drives the mover to move up and down to cut the magnetic induction lines and generate current.
The pulley assembly consists of a movable pulley, two fixed pulleys and a movable pulley motion guide. The fixed pulleys are fixed on the door frame, the movable pulley can slide up and down along the motion guide, and the motion guide is provided with an adjustable limit stop to control the movement of the movable pulley. One end of the cable is fixed on the gantry, and the other end goes around the movable pulley and two fixed pulleys in turn, and is connected to the upper end of the mover in the linear power generation system. The lower end of the movable pulley is connected with the float, and the float directly drives the mover of the linear power generation system to move through the movable pulley, cable and two sets of fixed pulleys. The introduction of the pulley assembly increases the mover to several times as fast as the float, thereby realizing the goal of speed increase. The increase of the mover's velocity raises the cutting speed of the coil, and thus improves the power generation efficiency of the device.

\subsection{Swing wave-making system}

In order to verify the effectiveness of the pulley-buoy accelerated type linear wave power generation system, a swing wave-making system is built to evaluate the electricity generation performance of the system through wave simulation. The swing wave-making system, as shown in Figure 2, consists of a motor driving control system, a motor driving system and a wave-simulating system. The motor driving system mainly includes a crank connecting rod and an asynchronous AC motor. The wave-simulating system mainly includes a wavemaking tank and a swing plate.

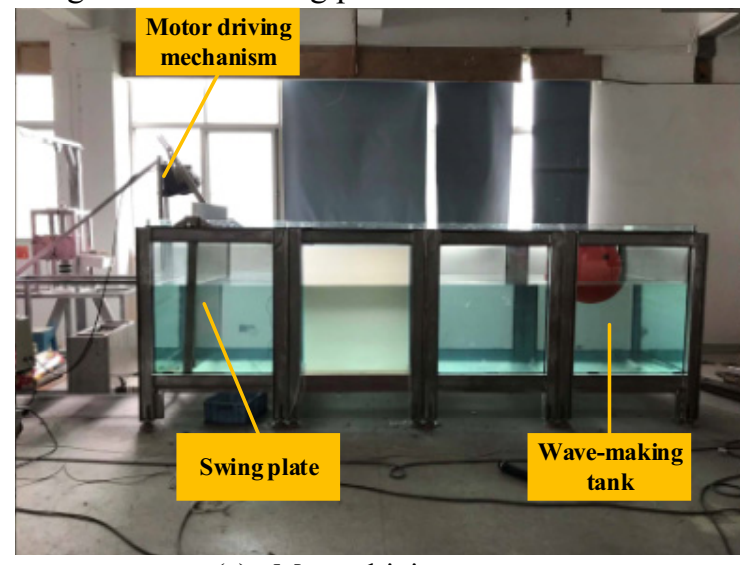

(a) Motor driving system 


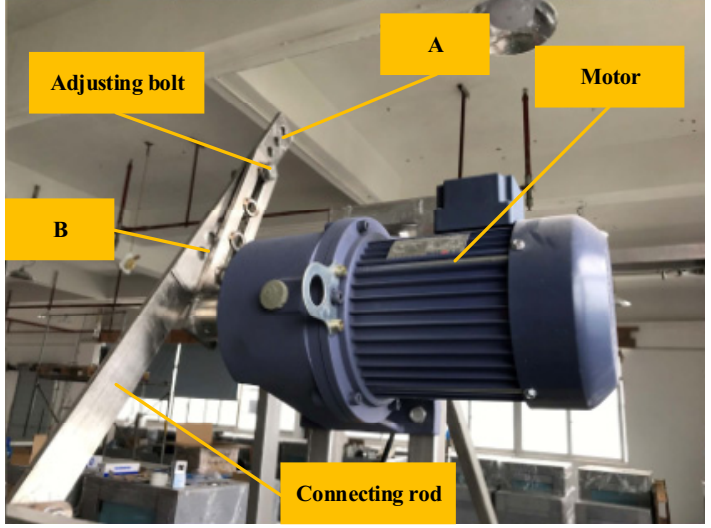

(b) Wave-simulating system

Figure 2 Swing wave-making system

The basic parameters of the wave-making tank are set to $4 \mathrm{~m} \times 1.2 \mathrm{~m} \times 1.2 \mathrm{~m}$, and the basic parameters of the swing plate are $1.5 \mathrm{~m} \times 1.15 \mathrm{~m} \times 0.03 \mathrm{~m}$. The swing plate is set on the long side of the tank, $0.3 \mathrm{~m}$ away from the edge of the tank. The lower end of the swing plate is hinged at the bottom of the tank, and the plate can swing back and forth around the fixed axis at the bottom. When the swing plate swings to the rear, it is perpendicular to the static water surface. A hinge point is arranged above the swing plate, which is connected with the crank connecting rod. The crank arm of the crank connecting rod is fixedly connected with the rotating shaft of the driving motor. When the motor rotates, the crank is driven to make a circular motion, and the swing plate is driven to swing back and forth through the connecting rod to generate simulated waves. The length of the connecting rod connected with the swing plate can be changed by adjusting the bolt, as shown in Figure 2(a). The crank arm is provided with a long hole, which can be used to adjust the fixed position of the connecting rod on the crank arm and change the swing angle of the swing plate, thereby creating simulated waves of different wave heights and wavelengths. When the connecting rod and the crank arm are connected through the adjusting bolt in the A hole, the moving connecting rod is longer, the swing angle of the plate is larger, and the generated waves have larger wavelengths and wave heights. When the connecting rod and the crank are connected in the hole B through the adjusting bolt, the swing angle of the plate is smaller, and the generated wave has a smaller wavelength and wave height. The motor driving control system is equipped with a frequency converter. By adjusting the input frequency of the motor, the speed of the motor and the motion cycle of the swing plate are changed, thereby creating simulated waves of different cycles. A test point is set 2 meters away from the swing plate along the long side of the tank, and a wave height meter is installed at the middle of the short side of the tank at the test point to measure the wave height. A transparent A0 coordinate paper is posted on the front of the tank at the test point, and a high-speed camera is set at a position parallel to the water surface directly in front of the tank to capture the wave motion and measure the wave length and period.

\section{Tank Experiment}

\subsection{Experiment process}

During the test, the positions and connection modes of the component are shown in Figure 3. The door-type frame is moved to the top of the wave-making tank, and the float is connected to the movable pulley and placed in the tank. The main performance parameters such as voltage and current during the test are measured by a digital electrical parameter measuring instrument, and the uncertainty analysis of the test measurement is shown in Table 1.

\begin{tabular}{ccc} 
Table 1 & Uncertainty analysis of test measurement 1 \\
\hline Parameters & Measuring instrument & $\begin{array}{c}\text { Uncertainty } \\
\text { degree }\end{array}$ \\
\hline $\begin{array}{c}\text { Voltage } \\
(\mathrm{U})\end{array}$ & $\begin{array}{c}\text { Digital electrical } \\
\text { parameter measuring } \\
\text { instrument } \\
\text { Digital electrical } \\
\text { purrent (I) }\end{array}$ & $\frac{\delta U}{U}=0.1 \%$ \\
& $\begin{array}{c}\text { pameter measuring } \\
\text { instrument }\end{array}$ & $\frac{\delta I}{I}=0.1 \%$ \\
Power (P) & - & $\frac{\delta P}{P}=0.14 \%$ \\
\hline
\end{tabular}

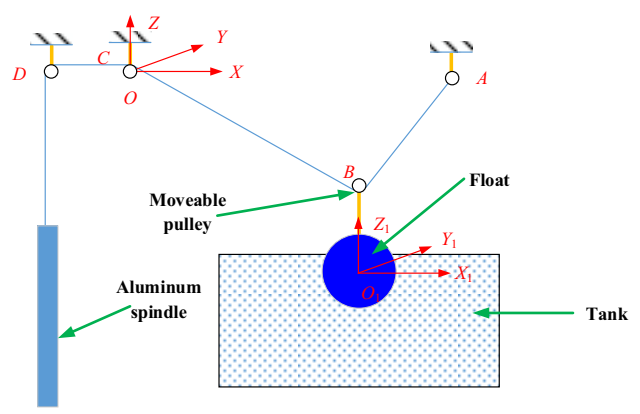

Figure 3 Schematic diagram of the test bench

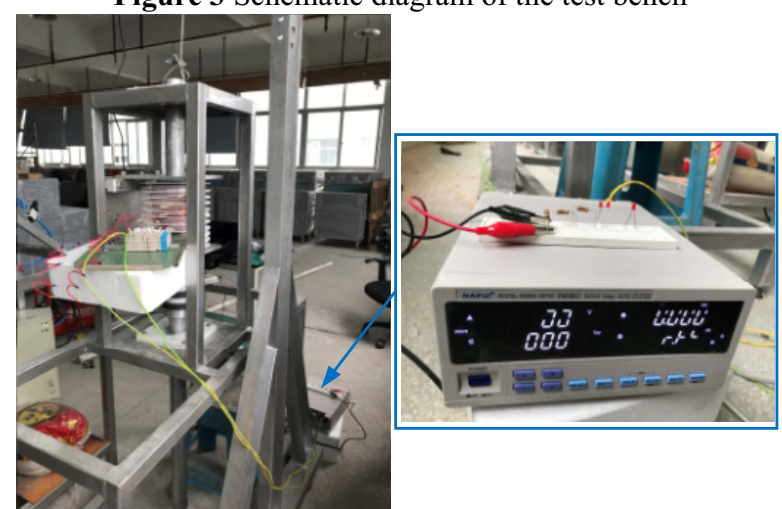

Figure 4 Linear power generation system and digital electric parameter measuring instrument

The experiment studies the influence of the number of the stator coil on the generation power of the linear power generation system under fixed wave conditions. The test is conducted as follows:

1) Install 4 ring magnets and 1 stator coil on the aluminum spindle of the linear power generation system, and connect the coil to the digital electrical parameter measuring instrument, as shown in Figure 4; 
2) In order to achieve fixed wave, the output frequency of the control inverter of the drive motor is adjusted to be unchanged, that is, the speed of the drive motor is controlled to be unchanged, and the period of the simulated wave is constant. Make sure the length of the crank of the connecting rod mechanism is fixed, so the swing angle of the plate is fixed, so as to make sure the wave height and wavelength of the simulated wave are constant.

3) Put a spherical float with a diameter of $850 \mathrm{~mm}$ in the wave-making tank, and turn on the power to start the driving motor. The wave-making swing plate and the float in the tank begin to move regularly. After the system is stable, measure and record the current and voltage of the linear power generation system and calculate the power generation;

4) Keep the number of ring magnets on the mover unchanged, increase the number of stator coils to 2, 3, 4, 5 , and 6 , repeat the above test steps, test the power generation of the same float under fixed wave conditions, and explore the influence of the coil number on the power generation of the system.

\subsection{Experiment results}

Under fixed wave conditions, the influence of the number of stator coils on the power generation of the accelerated-type wave power generation system is shown in Figure 5. It can be seen from Figure 5 that during the effective recorded stable operation period, when the number of stator coil is unchanged, the scatter trajectory of the system's generated power changes over time in a sawtooth shape. This is because the mover of the linear generation system is composed of a ring magnet, and the magnetic induction intensity of cutting the magnetic induction lines is the strongest when the ring magnet and the coil are on the same plane. As the mover moves in the direction away from the coil, the magnetic induction intensity at the coil weakens gradually, and the generation power of the system decreases gradually. When the mover moves in the direction close to the coil, the magnetic induction intensity at the coil increases gradually, and the generation power of the system increases gradually. Therefore, when the mover periodically moves under the drive of the float, the power generation of the system oscillates between the maximum value and the minimum value, showing a sawtooth shape. When the number of the stator coil is changed, it can be seen that the generated power amplitude and trend line corresponding to the number of coils from 1 to 6 gradually increase, indicating that increasing the number of the coils can better improve the power generation performance of the system. Figure 6 shows the relationship between the calculated average power generation of the system and the number of stator coils. It can be seen that as the number of coils increases, the average power generation of the system shows a linear increase trend. It further proves that increasing coils will effectively improve the power generation performance of the accelerated-type wave power generation system and increase its wave energy conversion efficiency.

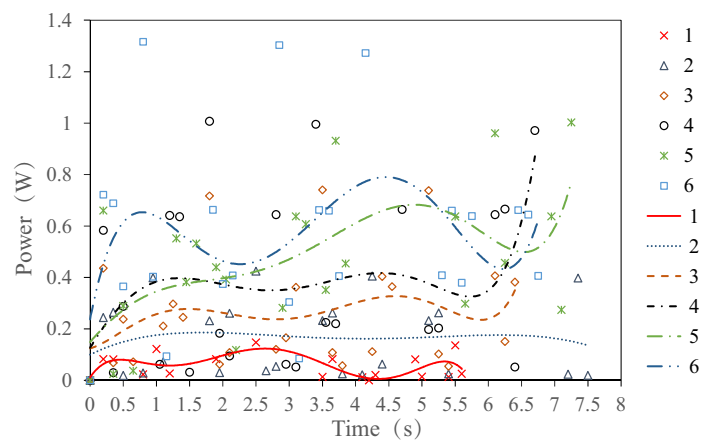

Figure 5 Generation power of the system corresponding to different numbers of coil

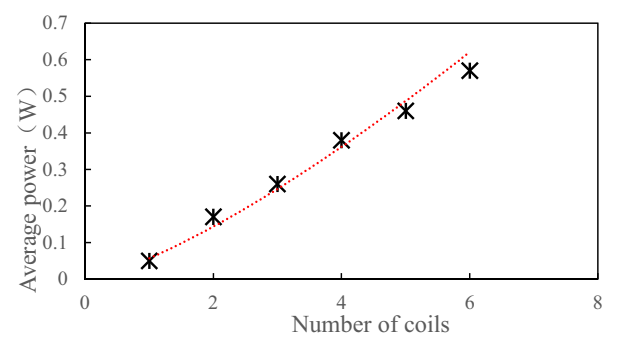

Figure 6 The average generation power of the system corresponding to different numbers of coils

\section{Conclusion}

Since traditional direct-drive wave power generation system has a low conversion efficiency, this paper proposed a novel pulley-buoy accelerated-type linear wave power generation system. In the generation system, the oscillating float was directly connected with the mover of the linear power generation system, and the wave energy was directly converted into electrical energy without energy transfer process. What's more, the pulley assembly increases the mover's velocity of cutting the magnetic induction lines for several times by increasing the velocity of the float, thereby improving the generation capacity and the wave energy conversion efficiency of the linear generation system. In order to verify the feasibility and effectiveness of the pulley-buoy accelerated-type linear wave power generation system, an undersized generation system and a swing wavemaking system were built under laboratory conditions. The experiment explored the influence of the number of the stator coils on the generating power of the pulleybuoy accelerated type linear wave power generation system, and the results show that:

1) For the same float and fixed wave conditions, when the mover of the device moves periodically under the drive of the float, the power generation of the system oscillated between the maximum value and the minimum value, showing a sawtooth shape.

2) As the number of the coils increased, the average power generation of the system showed a linear increase trend. 
3) In general, within the scope of this research, increasing the number of stator coils to a certain extent can effectively improve the wave energy conversion efficiency and the power generation performance of the system. The experimental research verified the feasibility and effectiveness of the pulley-buoy accelerated type linear wave power generation system, and provided valuable experience for the practical application and efficient operation of the wave energy power generation system.

\section{Acknowledgments}

The authors gratefully acknowledge the support of the Natural Science Foundation of Fujian Province, China (Grant No. 2018J05088), the Foreign Cooperation Projects of Fujian science and Technology Department (Grant No. 2020I0021), the Scientific Research Foundation of Jimei University (Grant No. ZQ2017005), Training Program of the National Natural Science Foundation of Jimei University (ZP2020047) and the Young and Middle-aged Teacher Education Scientific Program of Fujian Province (Grant No. JAT200250).

\section{References}

1. S. Qiu, K. Liu, D. Wang, J. Ye, F. Liang. A comprehensive review of ocean wave energy research and development in China, Renew. Sust. Energ. Rev. 113, (2019).

2. A. Falcão Wave energy utilization: A review of the technologies, Renew. Sust. Energ. Rev. 14, 3 (2010).

3. R. Ahamed, K. McKee, I. Howard. Advancements of wave energy converters based on power take off (PTO) systems: A review. Ocean eng. 204, (2020).

4. Y. Lin, J. Bao, H. Liu, W. Li, L. Tu, D. Zhang. Review of hydraulic transmission technologies for wave power generation. Renew. Sust. Energ. Rev. 50, (2015).

5. A. Clément, P. McCullen, A. Falcão, A. Fiorentino, F. Gardner, K. Hammarlund. Wave energy in Europe: current status and perspectives. Renew. Sust. Energ. Rev. 6, 5 (2002).

6. S. Sheng, K. Wang, H. Lin, Y. You, Z. Wang, A. Chen, J. Jiang, W. Wang, Y. Ye. Model research and open sea tests of $100 \mathrm{~kW}$ wave energy convertor Sharp Eagle Wanshan. Renew Energy 113, (2017).

7. S. Huang, S. Sheng, Y. You, A. Gerthoffer, W. Wang. Numerical study of a novel flex mooring system of the floating wave energy converter in ultra-shallow water and experimental validation. Ocean eng. 151 (2018).

8. Z. Liu, N. Qu, Z. Han, J. Zhang, M. Li, H. Shi. Study on energy conversion and storage system for a prototype buoys-array wave energy converter. Energy Sustain Dev. 34 (2016).

9. Y. Gu, D. Xie, Z. Geng. Hydrodynamic analysis of wave power generation devices of array buoy type, J. Hydro. Eng. 35, 8 (2016). (in Chinese).
10. L. Zhang, W. Guo, S. Wang. Hydrodynamic performance optimization of a point absorber. Journal of Harbin Institute of Technology 47, 7 (2015). (in Chinese).

11. H. Zhang, B. Zhou, C. Vogel, R. Willden, J. Zhang, J. Geng. Hydrodynamic performance of a dualfloater hybrid system combining a floating breakwater and an oscillating-buoy type wave energy converter. Appl Energy 259 (2020). 